This is a post-peer-review, pre-copyedit version of a Journal article published in the Research in Science Education

The final authenticated version is available online at:

10.1007/s11165-019-09885-x 


\title{
A Systematic Approach to Designing, Implementing, and Evaluating Learner-Generated Digital Media (LGDM) Assignments and their Effect on Self-Regulation in Tertiary Science Education.
}

\begin{abstract}
This study explored the self-regulation strategies and learning experiences of undergraduate science students completing LDGM assignments that had been implemented using a theory-driven, systematic approach. The rationale for using LGDM in science education is to facilitate student learning of complex scientific concepts through the multimodal representation of content using digital media. The study was conducted in seven science subjects from first to third year in Autumn 2017, using a sample of 348 undergraduate science students attending a university located in Sydney, Australia. All the participants were enrolled in subjects that required them to communicate complex scientific concepts using digital media. Training on LGDM was conducted online $(n=199)$ and in blended mode $(n=149)$. The study used a mixedmethods approach with a validated self-regulation questionnaire, LMS logs, assessment scores, group contribution data, open-ended questions, and interviews. Online students were more likely than blended students to report using self-regulation strategies for goal setting, time management, task strategies, and help-seeking. Data triangulation revealed that participation in LDGM assignments was perceived by students to contribute to their science content knowledge, provide them with digital media skills, and nurture their capacity for working in groups. The findings of this study have implications for how LDGM is deployed in science education.
\end{abstract}

Keywords: Learner-generated digital media, digital media assignments, multimedia assignments, self-regulation, science education.

\section{Introduction}

Digital technologies are reshaping the way people learn, socialise, and communicate. Evidence of this change can be seen with the rise of platforms such as Facebook (Manzi et al., 2018), Twitter (Weller, Bruns, Burgess, Mahrt \& Puschmann, 2014), Instagram (Salomon, 2013), and Linkedln (Cho \& Lam, 2017). Educators have identified the need for $21^{\text {st }}$-century professionals to be competent in communicating in the digital space (Alexander, Adams, \& Cummins, 2016; Hobbs, 2018; Shen et al., 2018). Providing students with digital media assignments is seen as an essential strategy for enhancing digital communication skills (Alexander et al., 2016; Hobbs, 2017; Potter \& McDougall, 2017). In science education, the promotion of digital media assignments has the following aims: (i) facilitate student learning of complex scientific concepts via multimodal representation of content using digital media; (ii) develop critical, problemsolving, and research skills while building the storyboard; (iv) develop digital media literacies; (v) expose students to teamwork, collaboration, and conflict resolution; (vi) help students to exercise cross-cultural communication, cultural sensitivity, and 
understanding of diversity (Coulson \& Frawley, 2017; Jablonski, Hoban, Ransom \& Ward, 2015; Nielsen, Georgiou, Jones \& Turney, 2018; Pearce \& Vanderlelie, 2016a).

The term Learner-Generated Digital Media (LGDM) refers to any digital media artefact developed by students to showcase their learning (e.g. podcast, digital story, animation, or video) (Reyna, Meier, Geronimo, \& Rodgers, 2016). Early use of LGDM was in teacher education courses, LGDM was used as a reflective tool (Kearney, 2013; Kearney \& Schuck, 2005; Rich \& Hannafin, 2009). In science education, there has been a different focus, with an emphasis on active learning, inquiry, and research approaches (Hoban, Nielsen, \& Shepherd, 2015). Areas of research on LGDM include biology (Pirhonen \& Rasi, 2016), computer programming (Powell \& Robson, 2014; Vasilchenko et al., 2017), health sciences (Pearce \& Vanderlelie, 2016b), pharmacology (Henriksen, Henriksen, \& Thurston, 2016; Nielsen, Hoban, \& Hyland, 2017; Reyna et al., 2016), geology (Reyna, Horgan, Ramp, \& Meier, 2017), mathematics (Calder, 2012; McLoughlin \& Loch, 2012), and engineering (Anuradha \& Rengaraj, 2017). These studies represent early attempts to explore LGDM in the classroom. There is an emerging consensus on the need for rigorous approaches to be adopted in evaluation studies of LDGM in educational settings (Hoban et al., 2015; Pirhonen \& Rasi, 2016; Potter \& McDougall, 2017).

According to the literature, the design, implementation, and evaluation of Learner Generated Digital Media have tended not to follow a theory-driven, systematic approach (Hoban et al., 2015), meaning that the intervention did not follow a plan or use theoretical models to inform the assessment task design. Key elements that have been missing in the design of LDGM in educational settings include the training of students in digital media creation, identification of appropriate digital media types, linking the task with learning objectives, and the development of appropriate marking rubrics (Reyna, 2016). Failure to consider these elements can result in a range of negative outcomes for students. As an example, if the digital media training needs of students are not taken into consideration, this may lead to student apprehension and anxiety (Coulson, 2017; Pearce, 2014). With regard to the implementation of LDGM, it is essential to communicate the requirements and expected outcomes of the task to students, including how the assessment task is designed and the reasons why they need to learn how to use digital media. These elements may help promote student engagement and understanding of the value of the learning task (Phillips, McNaught, \& Kennedy, 2012). Evaluation means collecting data to assess and improve the student experience. Evaluation can capture the skills that students have acquired, including digital media skills, knowledge construction, attitudes toward digital media for learning, understanding of the assessment task, and open-ended comments.

It has been suggested (Buckingham, 2007) that digital media assignments have been implemented in the classroom as an opportunistic pedagogical agent, with the expectation that students will develop digital media production skills without formal training and support from educators. Digital media as a discipline has principles and practices that cannot be mastered without formal training (Arvidsson \& Delfanti, 2019; Martin \& Zahrndt, 2017; Reyna, Hanham, \& Meier, 2018). Therefore, expecting students 
to learn digital media production by engaging in LGDM assignments without training is misguided.

LGDM is considered under-theorised and under-researched (Hoban et al., 2015; Potter \& McDougall, 2017). Frameworks to implement LGDM in the classroom come from either the technological or the pedagogical perspective; the roles of educators and students are unclear. Scholars have proposed several models of good practice for video in the classroom. A comprehensive nine-stage model was developed by Kearney and Schunck (2005a) which focused on teaching strategies and peer learning structures. A limitation of the model is that it is difficult to contextualise in other disciplines. Later, a learning design model for digital stories was proposed based on the previous model (Kearney, 2009). Recent attempts to develop a framework for multimedia production in the classroom include the CASPA Model (Consume, Analyse, Scaffold, Produce, and Assess) (Blum \& Barger, 2018), and the AACRA (Access, Analyse, Create, Reflect, and Act) (Hobbs, 2017) model, which are useful frameworks to guide the implementation of digital media. However, there is still a need for models that consider student group dynamics, training, marking rubrics, and evaluation of student experiences.

To date, the research field has been dominated by qualitative methodologies, which have provided in-depth insights into the lived experiences of small cohorts of students working on LDGM assignments (Hoban et al., 2015). These studies have been essential for unpacking some of the complexities associated with the implementation of LDGM. Nevertheless, there is a need for studies that employ designs that allow for a more holistic understanding of the nature of Learner Generated Digital Media in Science subjects. Mixed-methods designs represent such an approach, because they involve the collection, and often the triangulation, of various sources of quantitative and qualitative data.

Educators outside of the creative disciplines (visual design, digital media, graphic design, and film) face challenges in designing, implementing, and evaluating LGDM assignments (Bader \& Lowenthal, 2018). These challenges are related to a lack of understanding of digital media production workflows and principles, such as storyboarding, colour theory, layout design, typography, and video editing applications (Reyna et al., 2018). For these reasons, it is common to see in the LGDM literature that digital media training has been neglected. It is essential to develop a systematic approach to LGDM in the classroom that identifies student training needs for digital media creation. With that approach, students will not only learn the subject content, but also develop practical digital media communication skills.

\section{Literature Review}

\section{Self-regulation}

In educational contexts, self-regulation covers the judgements, feelings, thoughts, actions, and strategies involved in achieving a learning goal (Zimmerman, 2002). From the perspective of social learning theory, self-regulation is a complex interaction of 
cognitive, metacognitive, behavioural, and environmental processes (Bandura \& Walters, 1977). Several studies have found that self-regulation is associated with motivation, academic performance, achievement (Azevedo \& Cromley, 2004), and depth of student thinking (Jenson, 2011). Studies have also shown that self-regulation can help students to focus on the learning process (Ottenhoff, 2011) and promote the acquisition of reflective and responsible competence (Sluijsmans, Brand-Gruwel, van Merriënboer, \& Bastiaens, 2002).

Self-regulation is a critical factor in higher education online courses (Agustiani, Cahyad, \& Musa, 2016; Bailey, Jaggars, \& Jenkins, 2015; Hodges, 2008; Pardo, Han, \& Ellis, 2016), in part because educators are not physically present (McMahon \& Oliver, 2001) and students need to be self-directed. Self-regulation is also vital in blended learning environments (Barnard, Lan, To, Paton, \& Lai, 2009; Broadbent, 2017; Kenney \& Newcombe, 2018). These modes of learning require high levels of motivation, selfefficacy, and persistence for success (Edwards, 2018; Kaufmann \& Buckner, 2018; Vanslambrouck, Zhu, Lombaerts, Philipsen, \& Tondeur, 2018). Students in online and blended environments need to be actively engaged leaders of their learning processes, so self-regulation has an essential role in ensuring they will engage with online resources and succeed in their learning. Self-regulated students monitor their learning and can identify and implement the strategies required to succeed (Miller, 2015).

Self-regulation processes are highly context-dependent (Zimmerman, 1998; Zimmerman \& Tsikalas, 2005). For instance, a survey instrument that is valid for traditional settings may be invalid for online settings due to the dramatic differences between the delivery modes and the student profiles (Barnard-Brak, Paton, \& Lan, 2010; Barnard et al., 2009). Online learners need to be more independent and selfdirected than blended or face-to-face learners (Barak, Hussein-Farraj, \& Dori, 2016; Kocdar, Karadeniz, Bozkurt, \& Buyuk, 2018). Online activities are open regarding time, pace, and content, which means that strategies such as time management and environmental structuring are required (Barak et al., 2016; Barnard et al., 2009; Broadbent, 2017). Only in the past decade has a self-regulation questionnaire for online and blended learning been validated (Barnard et al., 2009). In the literature, comparisons between students in these two settings are rare, and it is an area of research that needs attention to inform course design to maximise student performance. From the limited research, it appears that online learners use self-regulation strategies more often than blended learning students do (Broadbent, 2017).

Self-regulation is multidimensional, with a set of subscales used to measure the different dimensions of self-regulation. These subscales have been reviewed extensively (Barnard et al., 2009; Nota, Soresi, \& Zimmerman, 2004; Pintrich \& Zusho, 2007; Schunk \& Zimmerman, 1997; Zimmerman \& Schunk, 2011). One dimension of self-regulation, environment structuring, refers to strategies students use to organise their physical environment at home or elsewhere so that distractions are minimised (Zimmerman, 1995). Goal setting is considered a critical dimension of self-regulatory learning and refers to learners' goals for their studies (Pintrich, 1991). Time management is a dimension of self-regulation that includes scheduling, planning, and 
managing one's study time (Chen, 2002). Task strategies refers to the student's methods of learning, such as note-taking or preparing questions before classes or discussion forums (Zimmerman, 2002). Finally, help-seeking refers to pursuing academic help to promote learning (Lynch \& Dembo, 2004).

Previous research has highlighted the need to investigate self-regulation to better understand how students undertake digital media assignments (Reyna \& Meier, 2018b). The authors posited that digital media for learning requires the development of a high level of self-regulation and autonomy to complete tasks successfully. Students lacking self-regulation skills may not be able to handle the autonomy of the learning tasks and may not complete them successfully (Barnard et al., 2009).

There are several aspects involved in the production of LGDM digital media assignments - producing the content, planning a multimodal representation, and building the digital media artefact. Students need to set up a goal for the project, research a given topic, and write a storyboard. To do this, students need to control their environment to avoid distractions (e.g. put mobile phones on silent) and they need to develop task strategies (e.g. note-taking in classes or tutorials). Then, they have to review the training material on digital media production, using task strategies, time management skills, and possibly help-seeking from the Internet or resources such as YouTube videos. Students need to monitor their activities and time to ensure they deliver their LGDM by the due date. An important, and arguably overlooked, aspect is motivation. The learning curve to acquire digital media production skills is generally slow due to its time-consuming, iterative, and resource-intensive nature (Arvidsson \& Delfanti, 2019; Musburger \& Kindem, 2012; Sørensen \& Levinsen, 2014). Students need to be motivated to achieve a good result for their digital media project. Motivation is considered the sine qua non of self-regulation processes. Constructs such as selfefficacy (Pintrich \& Zusho, 2007), task value (Pintrich, 2004), attribution to failure (Licht \& Dweck, 1984), and anxiety (Zimmerman, 1989) have a direct effect on self-regulation.

\section{Theoretical frameworks to design LGDM assignments}

A practical workflow, flexible enough to apply to any digital media type across all disciplines, has been identified as necessary for implementing LGDM assignments systematically (Reyna \& Meier, 2018). Previous research by the authors developed a set of five frameworks to design LGDM assignments for tertiary science students which were transferable to other disciplines. Descriptions of these frameworks are provided below.

\section{The Digital Media Literacies Framework (DMLF)}

This framework defines the elements of digital media literacy required for the production of LGDM assessments in educational settings. The Digital Media Literacies Framework proposes that the creation of a digital artefact has three domains - conceptual, functional, and audiovisual. The conceptual domain relates to research to find evidencebased information and the creation of a storyboard. The functional domain represents the development of skills for the use of software and applications, for example, video 
editing software, animation software, and so on. Finally, the audiovisual domain covers digital media principles, 'the grammar of the 21st century'. All these domains need to be mastered to produce an engaging digital artefact (Reyna, Hanham, \& Meier, 2017).

\section{The Taxonomy of Digital Media Types}

The second framework is the Taxonomy of Digital Media Types, which incorporates and further extends the DMLF. The framework classifies the different digital media types according to the complexity of the production skills required to create digital media artefacts, ranging from the development of an audio podcast to a blended media artefact - a video containing animations, images, and motion graphics. It also helps academics to decide what type of media to use for their assessment tasks and it informs the development of marking rubrics. For example, under communication skills, the marking rubric for the LGDM task could have three sections - the conceptual, functional, and audiovisual domains (Reyna, Hanham, \& Meier, 2017).

\section{The Digital Media Principles Framework}

This model can be used to educate students and academic staff about digital media principles and how these principles can be applied in the production of LDGM assignments. Its development was informed by research in neuroscience, psychology, visual design, and multimedia learning (Mayer \& Moreno, 2002). The digital media principles articulated in the model include layout design, colour theory, typography, C.R.A.P principles (Contrast, Repetition, Alignment, and Proximity), image use, and video principles. The application of these principles is important for the creation of engaging digital media artefacts (Reyna, Hanham, \& Meier, 2018a).

\section{The LGDM Implementation Framework}

The three frameworks described above complement the LGDM Implementation Framework. This framework contains eight elements that guide the implementation of LGDM assignments in the classroom - pedagogy, student training, video hosting, marking scheme, group collaboration, feedback, reflection, and evaluation. It includes FAQs discussed in the classroom and is scaffolded with supporting material available in the Learning Management System (LMS) (Reyna \& Meier, 2018).

\section{A Framework to Evaluate Learning Through LGDM Assignments}

This framework uses a longitudinal, mixed-methods approach to examine changes in students' self-regulation processes over time and their relationship with individual and group performance in LDGM assignments. It captures group contribution data, Learner Management System (LMS) logs, and marks attained for the LGDM task. The qualitative components include open-ended questions, individual structured interviews, and focus groups. Methodological triangulation is used to evaluate the student learning experience in LGDM assignments (Reyna, Hanham, \& Meier, 2018c).

This research aimed to test the validity of these frameworks through the lens of selfregulation. Research questions were: (i) Are students self-regulating their learning when LGDM assignment design follows a systematic approach?; and (ii) How does a 
systematic approach guided by theoretical frameworks impact the overall student learning experience with LGDM assignments?

\section{Materials and methods}

The study used a mixed-methods approach (Tashakkori \& Teddlie, 2010), where quantitative and qualitative data were analysed using methodological triangulation to support the findings (Bekhet \& Zauszniewski, 2012). The study had full ethics clearance from the university (UTS HREC ETH16-1060).

\section{Participants}

The research was conducted in the Autumn session, March to June 2017, at the Faculty of Science in a metropolitan university in Sydney, Australia. The study was based on a total sample of 1,687 students distributed across seven subjects across first year (Health and Homeostasis, $n=697$ ), second year (Investigation of Human Remains, $n=78$; Geological Processes, $n=103$ ), and third year (Pharmacology 1, $n=295$; Neuroscience, $n=323$; Molecular Nanotechnology, $n=50$; Medical Imaging, $n=110$ ) which had implemented LGDM assignments. In all the cohorts, students were able to choose their preferred digital media type out of digital story, animation, or video because the theoretical models used applied across all of them. The mode of delivery for all cohorts was blended mode, i.e. face-to-face lectures in the classroom complemented by self-paced online activities. For LGDM training, two methods of delivery were used: online, where the students completed the instruction inside the Learning Management System; and blended, where students had a face-to-face lecture and engaged in revision with online materials. Both these models were required because one subject could not allocate face-to-face lectures due to timetable constraints.

The participants completed a self-regulation questionnaire at three time-points during the session - T1 (week 2), T2 (week 6), and T3 (week 10). The collection of demographic data took place at the end of T1 (gender, age, education, and English as an Additional Language). Additionally, at the end of T3, answers to open-ended questions were collected to capture student views on the LGDM task. These questions were: (i) What did you like about the digital media assignment?; (ii) What did you like less about the digital media assignment?; and (iii) Do you have any suggestions on how it can be improved? All students, except for one subject (Pharmacology 1), were allocated to groups to work on their LGDM assignments. Pharmacology 1 was the only group that created blogs; the other subjects created videos.

\section{Task learning design}

Learner-Generated Digital Media (LGDM) assignment design, implementation, and evaluation followed a systematic approach, using five previously developed frameworks. Figure 1 presents a workflow and explains the frameworks and how they were used in the current study. The first four frameworks were validated in a pilot study that found that students had a positive attitude towards the training and support in LGDM creation provided during the session (equivalent to the old term 'semester'). The training was 
designed using the Digital Media Literacies Framework, the Taxonomy of Digital Media Types, and the Digital Media Principles Framework. The LGDM implementation framework was also validated by student attitudes towards the LGDM assessment's design (Reyna \& Meier, 2018b). The last framework to evaluate learning with LGDM assignments was recommended in the previous study and trialled in this research. All of these models can be used for any digital media artefact, as they are flexible enough for use with audio podcast, infographic, animation, brochure design, website, blog, or video.

Figure 1: Theoretical frameworks that informed the learning design of the LGDM assessment task.

Model

Description

The model identifies three domains in the effective creation of LGDM assignments.

The digital media literacies framework (Reyna, Hanham, \& Meier, 2018)
Conceptual (Storyboard), Functional (use of software), and Audiovisual (digital media principles).
The taxonomy of digital media types (Reyna, Hanham, \& Meier, 2017)
The model presents a workflow of the three domains of the digital media production task and shows the complexity of the different digital artefacts from an audio podcast to the development of a blended media presentation.

The digital media
principles framework
(Reyna, Hanham, \&
Meier, 2018a)

The model presents the topics that student need to be trained on to produce effective LGDM assignments. These topics include layout design, colour theory, typography, use of images, C.R.A.P principles (Contrast, Repetition, Alignment and Proximity), and basic video techniques.

This framework helps educators and students to understand the flow of the LGDM assignment. It considers pedagogy, student training, video hosting and distribution, marking scheme, group collaboration, feedback, reflection, and evaluation.

A mixed-methods approach to collect data, from a validated self-regulation questionnaire, LMS logs, student marks, group work data, open-ended questions, and interviews. Data interpretation using statistics, thematic analysis, and methodological triangulation.

\section{Application}

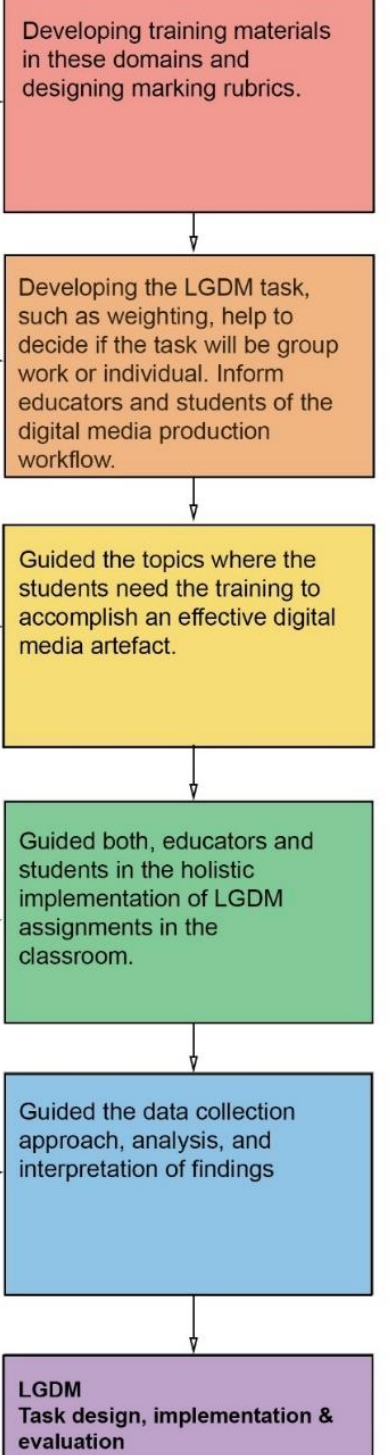

A framework to LGDM assignments (Reyna, Hanham, \& Meier, 2018b) 


\section{Self-regulation questionnaire}

A previously developed and validated twenty-item self-regulation questionnaire about LGDM assignments was used for the quantitative data collection (Reyna, Hanham, Vlachopoulos, \& Meier, 2019). The subscales included Task Strategies (TS), Goal Setting (GS), Environment Structuring (ES), Time Management (TM), Help-Seeking from People (HSP), and Help-Seeking from the Internet (HSI). The questionnaire used a four-point scale from 1 to 4 (strongly disagree, disagree, agree, and strongly agree). The self-regulation subscales were mapped against the LGDM Implementation framework (see Figure 1, green rectangles). Student Training was aligned with Task Strategies and Group Work was aligned with Goal Setting. Environment Structuring and Time Management and Feedback were aligned with Help-Seeking (Figure 1, green rectangles).

\section{Marking rubric}

All subjects used a standard rubric structure to measure communication skills in LGDM assignments, but weightings ranged from 20 to 30 percent of the total assignment score. The rubric comprised three sections, which were informed by the Digital Media Literacies Framework (Reyna, Hanham, \& Meier, 2018) and the Taxonomy of Digital Media (Reyna, Hanham, \& Meier, 2017). The conceptual domain included the goal of the presentation, synthesis of ideas, context, structure, flow, and use of references. The functional domain included the choice of software and device(s), smoothness of the presentation, no image pixellation, consistent use of transitions and effects, and audio quality. Finally, the audiovisual section of the rubric evaluated the application of the digital media principles (layout design, colour theory, C.R.A.P principles, typography, images, and video techniques). Also, the weighting for the content was different for each subject, measuring different learning outcomes and graduate attributes such as disciplinary knowledge, inquiry-oriented approaches, and professional skills.

\section{Group contribution data}

The SPARKPlus student peer-review tool was used to capture student perceptions of group member contributions. Inside the SPARKPlus application, a marking rubric to measure effective group contribution was designed and used across all subjects with the following criteria: (i) subject input for the project; (ii) punctuality and time commitment; (ii) contribution of original ideas; (iv) communication skills and working effectively as part of the team; and (v) focus on the task and what needs to be done. The students were given a sliding scale to grade themselves and then their peers, the 'levels of contribution' scale. The scale had five levels of contribution: Well Below Average (0-20\%); Below Average (20-40\%); Average (40-60\%); Above Average (60$80 \%$ ); and Well Above Average (80-100\%). Additionally, students needed to provide feedback to their peers. Due to the large number of datasets in this research, the feedback was not used for this paper.

The SPARKPlus application automatically calculated a rating that identified unbalanced groups. The Relative Performance Factor (RPF) is a measure of the degree of contribution to group work. This factor was calculated from a peer review of group members. The final mark for individual students was calculated by multiplying the 
group's mark by the student RPF factor. For instance, if a student got a group mark of 30 , but his/her RPF factor was 0.7 , his/her final mark was $30 \times 0.7=21$. Levels of contribution inside SPARKPlus for LGDM projects can be measured in three categories: Poor RPF<0.8; Acceptable 0.8 to 1.0; and Excellent >1.0 (Reyna et al., 2016).

\section{LMS logs}

Learning Management System (LMS) logs measuring student engagement with LGDM training materials were collected for T1 (week 2), T2 (week 6), and T3 (week 10). Unique visitors to the digital media files resources folder were recorded and converted to a percentage relative to the cohort size to give an estimate of the number of visits. The resources included a welcome video, FAQs about LGDM assignments, a module on digital media presentations, an example of a storyboard, links to previous LGDM assignments, and a marking rubric.

\section{Marks attained}

Marks were collected for all the groups and converted into percentages to evaluate whether they followed a normal distribution. Using marks alone as a measure of academic performance can be inconsistent and unreliable (Phillips, McNaught, \& Kennedy, 2012). Marks do not always truly reflect achievements, due to possible subjective biases in the marking process (Dunnigan, 2018). This may apply especially to this task because it requires marking of digital media and tutors may not have experience in marking LGDM assignments. The marks were triangulated with the other datasets.

\section{Interviews}

Twenty-eight interviews with four open-ended questions were conducted with students from the different cohorts to gauge their motivation to complete the LGDM assessment task. The first question (Did you feel you have the knowledge and skills to complete the LGDM project?) gauged self-perceptions of confidence, which have been found in previous research to be associated with self-regulation (Pintrich \& Zusho, 2007). The second question (How did you find the LGDM project's usefulness for your learning and development of skills?) measured task value, as students who attach a high value to an assignment generally use more in-depth cognitive and metacognitive strategies for learning (Pintrich, 2004). The third question (Did you feel there were uncontrollable factors beyond your knowledge that could affect the outcome of your LGDM project?) measured attribution to failure, as students who rate uncontrollable factors such as luck, ability, or task difficulty as their reason for failure or success do not exhibit learning tendencies (Licht \& Dweck, 1984). The last question (Did you feel anxious about the LGDM project?) gauged levels of anxiety, as it can negatively affect self-regulated learning by undermining cognitive and metacognitive learning processes (Zimmerman, 1989).

\section{Analysis of data}

Survey data on self-regulation beliefs were divided into two groups, students who received LGDM training online $(\mathrm{n}=199)$ vs blended $(\mathrm{n}=149)$. The available literature suggests that students who receive LDGM training online use self-regulation strategies 
differently to those who receive training in a blended learning mode (Barnard et al., 2009; Broadbent, 2017; Kocdar et al., 2018). Taking this into account, we did not aggregate the data or analyse them together. Quantitative data (questionnaire data, LMS logs, marks, and group contribution scores) were analysed using frequencies, descriptive statistics, and one-way ANOVA. The software used to analyse the data was IBM SPSS Statistics for Windows, Version 24.0. For qualitative data (open-ended questions and interviews), thematic analysis with NVivo, Version 11 was used to find categories. Data were interpreted using methodological triangulation, which links qualitative and quantitative data to make sense of the results (Gorissen, Bruggen, \& Jochems, 2013).

\section{Results}

Demographic characteristics of participants showed a ratio of $79 \%$ females to $21 \%$ males, of ages 17-28 (89\%), 29-40 (9\%), and 41-51 (2\%). Sixty-five percent were high school graduates, $10 \%$ were college graduates, $10 \%$ were trade/technical/vocational graduates, $13 \%$ had university degrees, and $2 \%$ were postgraduate students. Fortyseven percent of students had English as an Additional Language and 53\% were English native speakers.

\section{Overall self-regulation}

The final sample for the self-regulation questionnaire comprised students who responded at all three-time points (T1, T2, and T3). Out of 1,687 students, 348 responded to the self-regulation questionnaire (21\% response rate). Comparisons between cohorts were not possible due to sample size variability (Table 1). This sample was divided into online $(n=199)$ and blended $(n=149)$. The students who 'strongly disagreed' and 'disagreed' were considered as having non-self-regulated beliefs, while students who 'agreed' and 'strongly agreed' were regarded as having self-regulated beliefs. Of students who received online training in LGDM, 87\% had self-regulation beliefs, while $13 \%$ did not have self-regulation beliefs. Of students who received blended training in LGDM, $82 \%$ had self-regulation beliefs, while $18 \%$ did not have selfregulation beliefs. Overall descriptive statistics on self-regulation were calculated (Table 2) at $\mathrm{T} 1, \mathrm{~T} 2$, and $\mathrm{T} 3$.

Table1: Science subject cohorts that implemented LGDM assignments in Autumn 2017 and responded to the questionnaire at T1, T2, and T3.

\begin{tabular}{|llll|}
\hline Subject & N & Year & $\begin{array}{l}\text { Delivery } \\
\text { Mode }\end{array}$ \\
\hline Health and Homeostasis 1 & 199 & 1 & Online \\
Investigation of Human Remains & 52 & 2 & Blended \\
Geological Processes & 17 & 2 & Blended \\
Pharmacology 1 & 22 & 3 & Blended \\
Neuroscience & 33 & 3 & Blended \\
Molecular Nanotechnology & 13 & 3 & Blended \\
Medical Imaging & 12 & 3 & Blended \\
\hline
\end{tabular}


Table 2: Descriptive statistics for overall self-regulation for online $(n=199)$ and blended $(n=149)$ modes of delivery.

\begin{tabular}{|lllllll|}
\hline & & N & Mean & Median & Mode & SD \\
\hline Self-Regulation T1 & Online & 199 & 3.107 & 3.002 & 3.00 & .351 \\
& Blended & 149 & 3.002 & 2.967 & 2.95 & .329 \\
Self-Regulation T2 & Online & 198 & 3.025 & 3.000 & 3.00 & .395 \\
& Blended & 149 & 2.911 & 2.912 & 3.00 & .337 \\
Self-Regulation T3 & Online & 199 & 3.042 & 2.967 & 3.00 & .329 \\
& Blended & 148 & 2.947 & 2.912 & 3.00 & .444 \\
\hline
\end{tabular}

To assess whether there were statistical differences between the mean values for selfregulation in the subscales for online and blended delivery, one-way analysis of variance (ANOVA) was used. Students who received LGDM training online exhibited significantly higher scores for self-regulation beliefs in the following subscales at the times studied:

T1 (week 2): Task Strategies ( $F=8.492, P=0.004)$; Goal Setting ( $F=5.535, P=0.019)$; and Time Management $(F=24.389, P=0)$. T2 (week 6): Task Strategies $(F=4.278, P=0.039)$; Time Management $(F=13.687, P=0)$; and Help-Seeking from People $(F=11.261$, $P=0.001)$. T3 (week 10): Time Management $(F=5.734, P=0.017)$; and Help-Seeking from People $(F=6.090, P=0.014)$ (Table 3).

Table 3: One-way ANOVA for the effects of online and blended modes of delivery (LGDM training) on self-regulation subscales for T1, T2, and T3.

\begin{tabular}{|lllllll|}
\hline \multirow{2}{*}{ Variable Mean } & \multicolumn{7}{c}{ Online } & \multicolumn{2}{c|}{ Blended } & & \\
\cline { 2 - 6 } & $\mathbf{M}$ & SD & $\mathbf{M}$ & SD & F & Sig. \\
\hline T1 (week 2) & & & & & & \\
Task Strategies & 3.196 & .431 & 3.049 & .507 & $\mathbf{8 . 4 9 2}$ & $\mathbf{. 0 0 4}$ \\
Goal Setting & 3.107 & .467 & 2.981 & .530 & $\mathbf{5 . 5 3 5}$ & $\mathbf{. 0 1 9}$ \\
Environment Structuring & 3.081 & .459 & 3.030 & .499 & .978 & .323 \\
Time Management & 3.034 & .529 & 2.749 & .533 & $\mathbf{2 4 . 3 8 9}$ & $\mathbf{. 0 0 0}$ \\
Help-Seeking People & 3.025 & .415 & 2.934 & .492 & 3.482 & .063 \\
Help-Seeking Internet & 3.196 & .430 & 3.269 & .606 & 1.703 & .193 \\
& & & & & & \\
T2 (week 6) & & & & & & \\
Task Strategies & 2.969 & .509 & 2.848 & .586 & $\mathbf{4 . 2 7 8}$ & $\mathbf{. 0 3 9}$ \\
Goal Setting & 3.000 & .507 & 2.935 & .515 & 1.373 & .242 \\
Environment Structuring & 3.049 & .491 & 2.988 & .476 & 1.363 & .244 \\
Time Management & 2.931 & .541 & 2.703 & .603 & $\mathbf{1 3 . 6 8 7}$ & $\mathbf{. 0 0 0}$ \\
Help-Seeking People & 2.994 & .443 & 2.837 & .415 & $\mathbf{1 1 . 2 6 1}$ & $\mathbf{. 0 0 1}$ \\
Help-Seeking Internet & 3.182 & .514 & 3.155 & .494 & .231 & .631
\end{tabular}




\section{T3 (week 10)}

\begin{tabular}{lllllll|} 
Task Strategies & 2.969 & .609 & 2.851 & .642 & 3.071 & .081 \\
Goal Setting & 3.055 & .532 & 3.003 & .586 & .741 & .390 \\
Environment Structuring & 3.076 & .523 & 3.027 & .512 & .749 & .387 \\
Time Management & 3.010 & .569 & 2.858 & .604 & $\mathbf{5 . 7 3 4}$ & .017 \\
Help-Seeking People & 2.991 & .478 & 2.858 & .516 & $\mathbf{6 . 0 9 0}$ & .014 \\
Help-Seeking Internet & 3.189 & .543 & 3.085 & .632 & 2.746 & .098 \\
\hline
\end{tabular}

To assess the differences between self-regulation items in the subscales for online and blended delivery of LGDM training for T1, T2, and T3, one-way analysis of variance (ANOVA) was used. Table 4 presents the statistically significant items.

Table 4: One-way analysis of variance for the effects of online and blended modes of delivery on self-regulation subscales for T1, T2, and T3. Data only included items that had statistical significance.

\begin{tabular}{|c|c|c|c|c|c|c|}
\hline \multirow[t]{2}{*}{ Item } & \multicolumn{2}{|l|}{ Online } & \multicolumn{2}{|c|}{ Blended } & \multirow[b]{2}{*}{$\mathbf{F}$} & \multirow[b]{2}{*}{ Sig. } \\
\hline & $\mathbf{M}$ & SD & $\mathbf{M}$ & SD & & \\
\hline \multicolumn{7}{|l|}{ Task Strategies T1 } \\
\hline $\begin{array}{l}\text { I take notes from the digital media } \\
\text { lecture to be more prepared for the } \\
\text { task. }\end{array}$ & 3.260 & .537 & 3.09 & .557 & 8.738 & .003 \\
\hline $\begin{array}{l}\text { I visit the digital media resources } \\
\text { inside the LMS. }\end{array}$ & 3.140 & .562 & 2.91 & .716 & 10.732 & .001 \\
\hline \multicolumn{7}{|l|}{ Goal Setting T1 } \\
\hline $\begin{array}{l}\text { I set goals to help me manage my time } \\
\text { for engaging with my digital media } \\
\text { assignment. }\end{array}$ & 3.180 & .519 & 3.01 & .612 & 7.856 & .005 \\
\hline \multicolumn{7}{|l|}{ Time Management T1 } \\
\hline $\begin{array}{l}\text { I schedule regular times each week to } \\
\text { work on my digital media assignment. }\end{array}$ & 2.940 & .582 & 2.62 & .654 & 23.341 & .000 \\
\hline $\begin{array}{l}\text { I manage my time efficiently, so I am } \\
\text { not rushing around to finish at the last } \\
\text { minute. }\end{array}$ & 3.100 & .661 & 2.91 & .681 & 7.209 & .008 \\
\hline $\begin{array}{l}\text { I follow my planned schedule for } \\
\text { completing the digital media project. }\end{array}$ & 3.060 & .589 & 2.720 & .607 & 27.394 & .000 \\
\hline \multicolumn{7}{|l|}{ Task Strategies T2 } \\
\hline $\begin{array}{l}\text { I visit the digital media resources } \\
\text { inside the LMS. }\end{array}$ & 3.030 & .638 & 2.740 & .061 & 14.757 & .000 \\
\hline \multicolumn{7}{|l|}{ Help-seeking People T2 } \\
\hline $\begin{array}{l}\text { I find people who are knowledgeable } \\
\text { in subject content so that I can ask } \\
\text { them for help. }\end{array}$ & 2.970 & .618 & 2.800 & .682 & 6.441 & .012 \\
\hline $\begin{array}{l}\text { I share the difficulties I am having with } \\
\text { the digital media assignment with my } \\
\text { classmates. }\end{array}$ & 3.090 & .546 & 2.910 & .546 & 9.108 & .003 \\
\hline $\begin{array}{l}\text { I check with my classmates to find out } \\
\text { how I am doing on my assignment. }\end{array}$ & 3.070 & .575 & 2.890 & .585 & 7.661 & .006 \\
\hline $\begin{array}{l}\text { I check with my classmates to find out } \\
\text { what I am learning that is different } \\
\text { from what they are learning. }\end{array}$ & 3.03 & .597 & 2.82 & .636 & 9.529 & .002 \\
\hline \multicolumn{7}{|l|}{ Time Management T3 } \\
\hline $\begin{array}{l}\text { I schedule regular times each week to } \\
\text { work on my digital media assignment. }\end{array}$ & 2.930 & .647 & 2.750 & .775 & 5.847 & .016 \\
\hline
\end{tabular}




\begin{tabular}{|c|c|c|c|c|c|c|}
\hline $\begin{array}{l}\text { I follow my planned schedule for } \\
\text { completing the digital media project. }\end{array}$ & 3.060 & .589 & 2.880 & .669 & 4.679 & .031 \\
\hline \multicolumn{7}{|l|}{ Help-seeking People T3 } \\
\hline $\begin{array}{l}\text { I find people who are knowledgeable } \\
\text { in subject content so that I can ask } \\
\text { them for help. }\end{array}$ & 2.970 & .634 & 2.840 & .639 & 3.902 & .049 \\
\hline $\begin{array}{l}\text { I share the difficulties I am having with } \\
\text { the digital media assignment with my } \\
\text { classmates. }\end{array}$ & 3.060 & .601 & 2.890 & .653 & 6.222 & .013 \\
\hline $\begin{array}{l}\text { I check with my classmates to find out } \\
\text { what I am learning that is different } \\
\text { from what they are learning. }\end{array}$ & 3.040 & .582 & 2.86 & .728 & 5.903 & .016 \\
\hline
\end{tabular}

\section{Self-regulation and gender}

Regarding overall self-regulation for students who received LGDM online training, there was a statistically significant gender difference, with females at T2 scoring higher for self-regulation beliefs than males $(F=4.660, P=0.011)$. In contrast, no statistically significant difference by gender was found in overall self-regulation for students who received blended training for $\mathrm{T} 1, \mathrm{~T} 2$, and T3 ( $F=4.10, P=0.664 ; F=5.45, P=0.581$; $F=2.047, P=0.133$, respectively).

To further analyse the results, one-way ANOVA was conducted for the items in each self-regulation subscale, for both online and blended groups. Females in online settings scored higher for self-regulation beliefs at T2 than males in Environment Structuring ( $I$ choose a time with few distractions for working for my digital media assignment) ( $F=3.657, P=0.027$ ) and Time Management (I schedule regular times each week to work on my digital media assignment) ( $F=3.732, P=0.026$ ). Additionally, females scored higher at T3 for Help-Seeking from People (I share the difficulties I am having with the digital media assignment with my classmates) $(F=4.162, P=0.017)$ (Table 5).

Females in blended mode scored higher for self-regulation beliefs in Task Strategies at T1 and T3 (I take notes from the digital media workshop to be more prepared for the task; I visit the digital media resources inside the $L M S)$, T1 ( $F=3.330, P=0.039 ; \quad F=3.432$, $P=0.035)$, and T3 ( $F=5.896, P=0.003 ; F=3.818, P=0.024)$. Females also scored higher at T3 for Environment Structuring (I choose a time with few distractions for working for my digital media assignment) $(F=3.894, P=0.023)$ and Help-Seeking from People (I share the difficulties I am having with the digital media assignment with my classmates; I check with my classmates to find out what I am learning that is different from what they are learning) ( $F=4.829, P=0.009 ; F=3.456, P=0.034$, respectively) (Table 6).

Males who received blended training exhibited statistically significantly higher selfregulation belief scores at T1 and T2 than females for Help-Seeking from People, in the item: I check with my classmates to find out what I am learning that is different from what they are learning (T1: $F=5.137, P=0.007 ; \mathrm{T} 2$ : $F=4.527, P=0.012$ ) (Table 15). These results may not be representative, due to the large population of females in the current study. Overall population of females was $89 \%(n=272)$ and males $11 \%(n=71)$. For the online group, the percentage of females was $89 \%(n=174)$ and males $11 \%$ $(n=21)$ and for the blended group, females were 66\% ( $n=98)$ and males 34\% ( $n=50)$. It has been suggested that there is a difference between males and females in selfregulation strategies (Niemivirta, 1997; Wolters, 1999). This could affect the results and will be examined in the Discussion section. 
Table 5: One-way ANOVA for the effects of gender on self-regulation subscales at $\mathrm{T} 1$, T2, and T3 of students who received LGDM training online. Data only included items with statistical significance.

\begin{tabular}{|c|c|c|c|c|c|c|}
\hline \multirow[t]{2}{*}{ Item } & \multicolumn{2}{|c|}{$\begin{array}{l}\text { Female } \\
(\mathrm{N}=174)\end{array}$} & \multicolumn{2}{|c|}{$\begin{array}{l}\text { Male } \\
(\mathrm{N}=21)\end{array}$} & \multirow[b]{2}{*}{$\mathbf{F}$} & \multirow[b]{2}{*}{ Sig. } \\
\hline & $\mathbf{M}$ & SD & M & SD & & \\
\hline \multicolumn{7}{|l|}{ Environment Structuring T2 } \\
\hline $\begin{array}{l}\text { I choose a time with few distractions } \\
\text { for working for my digital media } \\
\text { assignment. }\end{array}$ & 3.01 & .594 & 2.71 & .644 & 3.675 & .027 \\
\hline \multicolumn{7}{|l|}{ Time Management T2 } \\
\hline $\begin{array}{l}\text { I schedule regular times each week to } \\
\text { work on my digital media assignment. }\end{array}$ & 2.82 & .625 & 2.52 & .814 & 3.732 & .026 \\
\hline \multirow{2}{*}{$\begin{array}{l}\text { Help-seeking People T3 } \\
\text { I share the difficulties I am having with } \\
\text { the digital media assignment with my } \\
\text { classmates. }\end{array}$} & & & & & & \\
\hline & 3.09 & .568 & 2.76 & .768 & 4.162 & .017 \\
\hline
\end{tabular}

Table 6: One-way ANOVA for the effects of gender on self-regulation subscales at $\mathrm{T} 1$, T2, and T3 for students who received LGDM training in blended mode. Data only included items with statistical significance.

\begin{tabular}{|c|c|c|c|c|c|c|}
\hline \multirow[t]{2}{*}{ Item } & \multicolumn{2}{|c|}{$\begin{array}{l}\text { Female } \\
(\mathrm{N}=98)\end{array}$} & \multicolumn{2}{|c|}{$\begin{array}{l}\text { Male } \\
(\mathrm{N}=50)\end{array}$} & \multirow[b]{2}{*}{$\mathbf{F}$} & \multirow[b]{2}{*}{ Sig. } \\
\hline & $M$ & SD & $\mathbf{M}$ & SD & & \\
\hline \multicolumn{7}{|l|}{ Task Strategies T1 } \\
\hline $\begin{array}{l}\text { I take notes from the digital media } \\
\text { workshop to be more prepared for the } \\
\text { task }\end{array}$ & 3.22 & .508 & 3.00 & .495 & 3.330 & .039 \\
\hline $\begin{array}{l}\text { I visit the digital media resources } \\
\text { inside the LMS. }\end{array}$ & 3.02 & .718 & 2.70 & .278 & 3.432 & .035 \\
\hline \multicolumn{7}{|l|}{ Help-Seeking People T1 } \\
\hline $\begin{array}{l}\text { I check with my classmates to find out } \\
\text { what I am learning that is different } \\
\text { from what they are learning. }\end{array}$ & 2.82 & .737 & 3.02 & .589 & 5.137 & .007 \\
\hline \multicolumn{7}{|l|}{ Help-seeking People T2 } \\
\hline $\begin{array}{l}\text { I check with my classmates to find out } \\
\text { what I am learning that is different } \\
\text { from what they are learning. }\end{array}$ & 2.81 & .651 & 2.88 & .558 & 4.527 & .012 \\
\hline \multicolumn{7}{|l|}{ Task Strategies T3 } \\
\hline $\begin{array}{l}\text { I take notes from the digital media } \\
\text { lecture to be more prepared for the } \\
\text { task. }\end{array}$ & 3.02 & .707 & 2.60 & .700 & 5.896 & .003 \\
\hline $\begin{array}{l}\text { I visit the digital media resources } \\
\text { inside the LMS. }\end{array}$ & 2.86 & .750 & 2.70 & 678 & 3.818 & .024 \\
\hline \multicolumn{7}{|l|}{ Environment Structuring T3 } \\
\hline $\begin{array}{l}\text { I choose a time with few distractions } \\
\text { for working for my digital media } \\
\text { assignment. }\end{array}$ & 3.05 & .569 & 2.82 & .629 & 3.894 & .023 \\
\hline
\end{tabular}




\begin{tabular}{|l|l|l|l|l|l|l|}
\hline Help-seeking People T3 \\
\hline $\begin{array}{l}\text { I share the difficulties I am having with } \\
\text { the digital media assignment with my } \\
\text { classmates. }\end{array}$ & 2.94 & .662 & 2.84 & .584 & $\mathbf{4 . 8 2 9}$ & .009 \\
$\begin{array}{l}\text { I check with my classmates to find out } \\
\text { what I am learning that is different } \\
\text { from what they are learning. }\end{array}$ & 2.86 & .720 & 2.70 & .678 & $\mathbf{3 . 4 5 6}$ & .034 \\
\hline
\end{tabular}

\section{LMS logs}

The LMS logged unique visitors to the LGDM resources folder of training material for students. These resources included a 'welcome' video, an online module on digital presentations, a PDF of FAQs, an example of a storyboard, and links to examples of LGDM projects from Spring 2016. Due to the limitations of the LMS, it was not possible to track student visits to each of these resource items. In T1 (week 2), 70 and 53 percent of students visited the LGDM resources, while 79 and 58 percent visited in T2 (week 6), and 77 and 67 percent in T3 (week 10), for online and blended modes, respectively.

\section{Marks attained}

Marks could not be compared because there were different markers and different rubrics aligned with different subject learning objectives. The data had a normal distribution. The marks were also analysed per subject, and all subjects had normal distributions for both online and blended cohorts.

\section{Group Contribution (RPF Factor - SPARKPlus)}

One-way ANOVA showed no significant differences between RPF Factors for the online and blended groups $(F=0.25, P=0.875)$. In both groups, a normal distribution of RPF factors was observed. The mean for RPF $<0.8$ was $2.6 \%$, for RPF $0.8-1.0$ was $51.3 \%$, and for RPF >1 was $46.1 \%$ across all subjects. RPF Factor data were also divided into years (first, second, and third) and one-way ANOVA was run, but no statistical differences were found $(F=0.120, P=0.887)$. Table 7 shows the RPF range: Excellent (>1.0); Acceptable (0.8-1.0); and Poor $(<0.8)$

Table 7: RPF Factor distribution by percentage across subjects undertaking the LGDM assignment in 2017 in the Faculty of Science.

\begin{tabular}{|lllllll|}
\hline RPF Range & Geo & HH1 & IHR & MI & MN & Neu \\
\hline $\begin{array}{l}>1 \\
\text { (Excellent) }\end{array}$ & 59.7 & 46.4 & 41.6 & 39.8 & 39.7 & 44.9 \\
$\begin{array}{l}0.8-1.0 \\
\text { (Acceptable) } \\
\begin{array}{l}<0.8 \\
\text { (Poor) }\end{array}\end{array}$ & 34.0 & 50.5 & 57.1 & 58.3 & 60.0 & 53.9 \\
\hline
\end{tabular}

\section{Open-ended questions}

A total of 442, 297, and 250 responses were received from students for questions: (1) What did you like about the digital media assignment?; (2) What did you like less about 
the digital media assignment?; and (3) Do you have any suggestions on how it can be improved?

In some cases, a single student answer was coded into a few themes. For instance, a student might say that they enjoyed learning digital media, the creativity aspect, and the group work experience. Responses from the online and blended groups were coded separately (Tables 8,9 , and 10).

Table 8: Student 'likes' about the Learner-Generated Digital Media (LGDM) assignment

\begin{tabular}{|lll|}
\hline What did you like about the digital media assignment? & \multicolumn{3}{c|}{ N } \\
\cline { 2 - 3 } & Online & Blended \\
\hline Learning digital media & 43 & 33 \\
Group work & 37 & 30 \\
Creativity & 39 & 21 \\
The learning experience & 41 & 17 \\
Fun assignment & 27 & 8 \\
Different assignment & 23 & 10 \\
Helped me to learn subject content via digital media creation & 22 & 7 \\
Interesting assignment & 13 & 11 \\
Using digital media for learning & 14 & 7 \\
The social aspect of the assignment & 9 & 9 \\
Learning the subject content & 10 & 6 \\
Making the digital media artefact & 8 & 7 \\
The satisfaction after digital media creation & 8 & 6 \\
Developing communication skills with technology & 7 & 5 \\
Everything & 6 & 5 \\
Development of critical thinking & 9 & 4 \\
Improving time management & 7 & 7 \\
Development of organisational skills & 7 & 4 \\
\hline
\end{tabular}

Table 9: What students 'liked less' about the Learner-Generated Digital Media (LGDM) assignment

\begin{tabular}{|lcc|}
\hline What did you like less about the digital media assignment? & \multicolumn{2}{c|}{ N } \\
\cline { 2 - 3 } & Online & Blended \\
\hline Time-consuming & 52 & 20 \\
Time to organise the assignment with the group & 21 & 19 \\
Difficult for students with no digital media skills & 16 & 19 \\
Positive comments & 13 & 12 \\
Assignment unclear & 15 & 3 \\
Nothing & 12 & 5 \\
Groups too large & 3 & 14 \\
The time to learn digital media skills & 8 & 7 \\
Everyone can't contribute equally & 10 & 6 \\
\hline
\end{tabular}




\begin{tabular}{|lll|}
\hline Not being digitally savvy & 9 & 6 \\
Challenging & 5 & 4 \\
Not being creative & 7 & 4 \\
Not relevant to my degree & 6 & 4 \\
Working together as a group & 5 & 4 \\
\hline
\end{tabular}

Table 10: Student suggestions to improve the Learner-Generated Digital Media (LGDM) assignment

\begin{tabular}{|c|c|c|}
\hline \multirow{2}{*}{ Do you have any suggestions on how it can be improved? } & \multicolumn{2}{|c|}{$\mathbf{N}$} \\
\hline & Online & Blended \\
\hline No, is good & 51 & 30 \\
\hline Additional training on creating video & 43 & 10 \\
\hline Smaller groups & 0 & 23 \\
\hline More clear instructions & 20 & 2 \\
\hline Video to be longer & 9 & 10 \\
\hline Individual assignments & 7 & 7 \\
\hline Don't do it & 2 & 8 \\
\hline Show video examples in the classroom & 6 & 4 \\
\hline Students to choose their groups & 3 & 7 \\
\hline University to provide software to edit video & 3 & 4 \\
\hline Teach more about copyright & 3 & 2 \\
\hline
\end{tabular}

\section{Interview data}

Did you feel you had the knowledge and skills at the time you started the digital media project?

Three themes emerged in the responses to this question. Inexperience with Digital Media was a prominent theme, where most of the interviewees indicated that they had limited or no previous experience with digital media production. Help-seeking was a theme which reflected the strategies interviewees used to acquire skills relevant to accomplishing the LGDM task. These included accessing resources on the Learning Management System (e.g. digital media resources folder), searching the Internet, and help-seeking from peers in their group and those who had completed the assessment task in previous sessions. Group support was a theme which referred to the importance of the social and instrumental support that working together with peers in groups provided to students. Social support was about positive social reinforcement, for instance, encouragement and motivation of group members as they worked on the assignment. Instrumental support referred to group members assisting with technical aspects of the assignment, such as video editing.

In what ways did you find the digital media project useful for your learning and development of skills? 
Three themes emerged in the responses to this question. Acquisition of digital media skills was a prominent theme and reflected interviewees' belief that the process of undertaking the digital media assignment equipped them with digital media skills that they did not previously possess. Notably, most of the interviewees did not mention the specific skills gained (e.g. video production), but talked about acquiring digital skills in a more general sense. Acquisition of collaborative learning skills was another theme, referring to the skills students developed through the experience of working in groups, including skills related to collaborative problem-solving and conflict management. Enhancement of learning through digital media was a theme, referring to how digital media functioned as a tool for learning. For example, researching information online and then producing a storyboard helped to consolidate and structure knowledge. Also, translating the storyboard using multimodality (e.g. transforming concepts into a role play or creating an animation to explain a process) was identified by interviewees as a benefit of using digital media for learning. Digital media as a distraction was a theme mentioned by a couple of students who believed that digital media was not useful for their learning. When we looked at the cohorts which these participants belonged to, they were ones in which the assessment task was worth only $10 \%$ of the total mark.

Did you feel there were uncontrollable factors beyond your knowledge that could affect the outcome of your digital media project?

The interviewees mentioned several potential uncontrollable factors, including availability of fellow group members, cost of digital media applications, deadlines for the assignment, and not all group members having social media accounts. Although these were identified as potential uncontrollable factors, most of the participants believed that these obstacles could be overcome. Indeed, most of the interviewees suggested that they were able to exercise a high level of control over most aspects of the LGDM assignment (e.g. assigning roles, choosing the digital media type, scheduling and attending meetings, learning different software and applications, and so on) and submitting the LDGM assignment on time.

\section{Did you feel anxious about the digital media project?}

Most of the interviewees indicated that they were not anxious about the LGDM task, despite most of them having limited or no previous experience with digital media production. Notwithstanding this, there were three themes associated with anxiety: anxiety as a motivator; choice-induced anxiety; and assignment-induced anxiety. Anxiety as a motivator: interviewees acknowledged that they felt anxious about the assignment, though this anxiety was viewed as a motivator to ensure that they completed their part of the task on time. Assignment-induced anxiety: interviewees felt anxious in the initial phase of the assignment, due to having limited or no knowledge of how to put together a digital media project. Choice-induced anxiety: some interviewees felt anxious due to the vast range of digital media choices available to them and were unsure about which digital media products were most suitable for their projects. 


\section{Discussion}

Digital media production is inherently complex, time-consuming, iterative, and resourceintensive (Arvidsson \& Delfanti, 2019; Musburger \& Kindem, 2012). LDGM tasks require students to engage in goal setting, task strategies, environmental structuring, and helpseeking, which are all dimensions of self-regulation (Reyna et al., 2019). To date, implementation of LDGM across several disciplines, including science, has not adopted a systematic approach guided by theoretical frameworks (Reyna \& Meier, 2018a, 2018b). Several streams of data collected for this study strongly suggest that students engaged in self-regulation strategies when undertaking LDGM assignments which had been implemented using a theory-driven, systematic approach. The data from the study show that students are reporting the use of various self-regulation strategies during the LGDM assignment, thus providing an answer to the first research question: Are students self-regulating their learning when LGDM assignment design follows a systematic approach?

The quantitative survey data showed that the majority of participants who received training online or in blended mode exhibited high scores for various dimensions of selfregulation. Notably, participants who received training online had higher scores for selfregulation strategies than did those students who received training in blended mode. This was evident for time management, task strategies, help-seeking from people, and goal setting. The results of this study align with a previous study by Broadbent (2017), which found that online students used self-regulation strategies more often than blended learning students did, with the exception of help-seeking. In the Broadbent (2017) study, blended learning students were less likely to engage in help-seeking than online students, however as noted in the study, neither blended nor online students engaged in help-seeking very often. In this study, there is an emphasis on group work, which was not evident in the Broadbent study and may explain the different results concerning help-seeking. In this study, the absence of an instructor for the online students is likely to have compelled them to seek help from fellow group members and the Internet more often than the blended students, who had access to an instructor, did.

Further evidence of differences between online and blended learning students emerged from analysing LMS logs. The LMS logs provided information regarding the number of unique visitors per day to the digital media resources folder in the LMS. Based on the logs, at every time interval more online students accessed the digital media resources folder than did blended learning students. This result is likely a reflection of the fact that online students did not have face-to-face lectures and workshops, and therefore had to rely more heavily on the online resources (Wells \& Blincoe, 2015). Triangulating these two datasets was important. Reliance on a single source of data, such as questionnaires, can have limitations because of self-reporting biases (Johnson \& Morgan, 2016). In this study, the self-reported data suggesting that online students engage more often in self-regulation strategies than blended learning students appeared to be supported by the data from LMS logs. This result is consistent with previous research which showed that online students use learning resources more than blended students do (Wells \& Blincoe, 2015). 
Regarding gender, there were differences between females and males in terms of scores on various dimensions of self-regulation. Differences between females and males in self-regulation strategies have been reported in previous research (Bidjerano, 2005; Zimmerman \& Martinez-Pons, 1990). At various time intervals, female online students scored higher than males for task strategies, environment structuring, and help-seeking from people. In the blended mode, females scored higher than males for environment structuring and time management, but not for help-seeking from people. The finding that females report a greater propensity for time management and environmental structuring accords with previous research (Bidjerano, 2005; Zimmerman \& Martinez-Pons, 1990). Interestingly, males taught in blended mode scored higher than females for self-regulation beliefs in help-seeking from people. It is important to note that the literature on gender differences regarding self-regulation strategies is inconclusive (Pintrich \& Zusho, 2007). As an example, one study found that females tend to use help-seeking strategies more than males do (Virtanen \& Nevgi, 2010), while another study found no statistically significant difference for help-seeking between males and females (Bidjerano, 2005).

Group contribution data had a normal distribution and no statistically significant difference was found between the two groups, online and blended. For the majority of groups in the study, the contributions of group members, as measured by RPF Factors in SparkPlus, ranged from acceptable (51.3\%) to excellent (46\%). The RPF data aligns with the open-ended responses concerning what the participants liked most about the digital media assignment, with group work being highly rated by the participants. This also resonates with the interview theme, group support, which reflected the perceived importance of social and instrumental support that working in groups provided to students. Notwithstanding this, some data from the open-ended responses and the interviews - specifically from Neuroscience, where there were 6-8 students per group suggested that the groups were too large and requested smaller size groups. It has been suggested that four students is the optimum group size to achieve higher satisfaction in knowledge acquisition, learning performance, and skill development, particularly in oral presentation, paper writing, and problem-solving (Chou \& Chang, 2018). Previous research suggests that, as group size increases, group performance decreases due to factors like 'social loafing' (Kooloos et al., 2011; Suzuki et al., 2018). An interesting finding is that, although interviewees from the Neuroscience cohort reported that their groups were too large, group contribution measures captured through SPARKPlus found that the Neuroscience groups had relatively high RPF scores, suggesting healthy group contributions.

There were consistencies between the open-ended question data and the interview data. This was evident in several respects. In the open-ended responses, learning digital media was the most frequently cited aspect of the LDGM assignment that students liked. This aligned with the interview theme, acquisition of digital media skills, which reflected interviewees' belief that undertaking the LDGM assignment gave them digital media skills. It is important to reiterate that many of the participants indicated 
that, before taking the LDGM, they had limited or no knowledge of how to produce the digital media product for their assignment.

Another common thread between the open-ended responses and the interview themes was learning through digital media. Learning the subject content through digital media creation was cited, mostly by online students, as one of the critical aspects that students liked. Enhancement of learning through digital media was a theme from the interviews. The different phases of preparing a LDGM assignment, including storyboarding, transforming the content using a multimodal approach (e.g. converting the text into an animation or role-play), and producing a digital media artefact, likely required students to engage in a variety of cognitive processes that enhanced their learning. These are likely to include cognitive restructuring (Webb \& Mastergeorge, 2003), self-explanation (Johnson \& Mayer, 2010), and meaning-making (Hoban et al., 2015).

Regarding the logistic difficulties of working with others in a group, there was a common thread between the open-ended responses and the interview themes. Interviewees highlighted that availability of group members was a potential uncontrollable factor. In the open-ended responses, finding times to organise the assignment with their group was frequently rated as one of the aspects that participants disliked about the LDGM assignment. Logistical issues such as availability of group members and finding times to meet have also appeared in previous research as negative aspects of working in groups (Pauli, Mohiyeddini, Bray, Michie, \& Street, 2008). Although not mentioned in the interviews, in the open-ended responses the time-consuming nature of the LDGM was the most frequently cited aspect that students liked least. The time-consuming nature of digital media production has been identified in previous research as a factor related to student anxiety and apprehension about LDGM assignments (Anderson, 2013; Coulson \& Frawley, 2017; Pearce \& Vanderlelie, 2016b).

The discussion in the preceding paragraphs has provided insights which address the second and final research question: (2) How does a systematic approach guided by theoretical frameworks impact the overall student learning experience with LGDM assignments? The implementation of LDGM was beneficial for most students in the study, facilitating the advancement of their scientific discipline knowledge, digital media skills, and skills for working in groups. It is also worth noting that the marks for the LDGM followed a normal distribution, which suggests that the theoretically driven implementation of LDGM likely did not have a detrimental impact on student achievement.

\section{Conclusion}

The purpose of the current study was to explore the validity of a novel systematic approach using practical frameworks to design, implement, and evaluate LGDM assignments in science subjects. Before discussing the implications of this research, it is essential to acknowledge the limitations of the study. First, the datasets included both online and blended learning students for the LGDM task. In practical terms, all students were in blended mode, although the training for the LGDM assessment task was given 
in both online and blended mode. Although the data were analysed separately, the online students were undertaking first-year subjects, while the blended students were taking second- and third-year subjects. Splitting the blended learning sample into subject cohorts was not appropriate due to reduction of the sample size. Second, the sample mainly comprised females (79\%), so the differences found between females and males regarding self-regulation strategies need to be interpreted with caution. Third, we did not directly capture how students interacted with each other, either online or in the blended mode, as they worked on the tasks. This issue was beyond the scope of this research, but it would be useful in future research to understand student roles in their groups and map this against self-regulation processes. Fourth, all participants were from a single higher education institution. To increase the generalisability of the research, future studies should involve participants from a broader range of randomly sampled universities. Fifth, the fact that there was no control group for comparison is also a limitation. Using a control group may be ethically problematic because it could potentially disadvantage some students.

Notwithstanding these limitations, this study has several important implications. Researchers and practitioners now have a set of frameworks to guide the systematic design, implementation, and evaluation of LDGM in the discipline of science. This is a significant contribution because the deployment of LDGM in science, and other disciplines, has so far been done without using empirically tested theoretical frameworks. Educators implementing LDGM now have an evidence-based workflow to guide them. It is important to emphasise that these theoretical frameworks are flexible and can be adapted to different contexts. Educators may not always need to use all the frameworks together. As an example, an educator might already have implemented LDGM assignments, but not included a training component to train students in digital media skills. That educator could draw on the Digital Media Principles Framework (see box 3 of Figure 1) (Reyna et al., 2018) as a resource to guide student training, e.g. layout design, colour theory, typography, use of images. As another example, if educators or students are unsure of which digital medium to choose for the LGDM assessment task, they can consult the Framework for Digital Media Types (see box 2 in Figure 1) (Reyna et al., 2017). Another implication of this study concerns the evaluation of students' self-evaluation strategies as they work in groups on LDGM assignments. Self-regulation is an important component of student motivation and self-directed learning. Researchers and practitioners now have a validated tool to measure different dimensions of self-regulation. A survey could be deployed at a particular time-point (e.g. week 1 , week 3 etc.), which could provide educators with insights into aspects of selfregulation, for example, goal setting or time management, that might need to be strategically targeted for improvement. For instance, groups in which members are having difficulties with time management could be identified through the survey and then assisted by an educator who could employ scaffolding strategies to improve time management skills in relation to the task.

Current research in science education identifies the need to develop a better understanding of the context in which LGDM assessments are used, the pedagogy behind them, and the learning processes involved (Nielsen et al., 2018). The various 
data sources used in this study confirmed that many students use self-regulation strategies when engaging in LDGM assignments. Scientific concepts can be challenging to understand and apply (Gurel, Eryılmaz, \& McDermott, 2015; Tümay, 2016). This could be due to the limited capacity of short-term memory and cognitive overload (Clark, Nguyen, \& Sweller, 2011). When students self-regulate their learning using LGDM assignments, they are likely to be better able to learn the content through storyboard creation, represent the content through meaning-making, and reinforce their content knowledge through digital media production (Reyna, 2019). These processes are likely to promote content retention in long-term memory and result in a higher-quality learning experience (Hoban et al., 2015).

Government agencies responsible for education (e.g. the NSW Department of Education, Australia: BOSTES, 2012) have recognised the need for scientists to be able to use multimodal approaches to communicate. Based on the data from this research, LGDM assignments guided by a systematic, theory-driven approach may enhance students' communication skills in the digital space (Jamani, 2011; Tang, Delgado, \& Moje, 2014).

Reflectively, this research is not claiming that LGDM assignments will improve the quality of student learning, because providing the evidence for that claim would be methodologically challenging. The view of the authors is that science education should be relevant to the times we live in. Digital media is integrated into all systems of information and knowledge production, interacting with almost every human activity. It offers transformative power to change society and facilitate the active participation of users in media production underpinned by collaborative processes. Digital media provides to its users the opportunity to express creativity and agency. New scientists, as $21^{\text {st }}$-century citizens, need fluent digital media production skills and the best way to develop these skills is with a systematic approach to LGDM assignments. Guesswork with LGDM will not guarantee student development of practical digital media production skills. The author hopes that the systematic approach to LGDM assignments in the science discipline explored in this research will inspire the new generation of science educators to foster digital media principles and effective production of digital artefacts. Science educators have a social responsibility to ensure that new science graduates are equipped with effective communication skills in the digital space. 


\section{References}

Agustiani, H., Cahyad, S., \& Musa, M. (2016). Self-efficacy and self-regulated learning as predictors of students academic performance. The Open Psychology Journal, 9(1).

Alexander, B., Adams, S., \& Cummins, M. (2016). Digital literacy: An NMC Horizon project strategic brief. Retrieved from

Anderson, J. (2013). Active learning through student film: a case study of cultural geography. Journal of Geography in Higher Education, 37(3), 385-398.

Anuradha, V., \& Rengaraj, M. (2017). Storytelling: Creating a Positive Attitude Toward Narration Among Engineering Graduates. IUP Journal of English Studies, 12(1), 32.

Arvidsson, A., \& Delfanti, A. (2019). Introduction to Digital Media: Wiley-Blackwell.

Azevedo, R., \& Cromley, J. G. (2004). Does training on self-regulated learning facilitate students' learning with hypermedia? Journal of educational psychology, 96(3), 523.

Bader, J. D., \& Lowenthal, P. R. (2018). Using Visual Design to Improve the Online Learning Experience: A Synthesis of Research on Aesthetics. In Learner Experience and Usability in Online Education (pp. 1-35): IGI Global.

Bailey, T. R., Jaggars, S. S., \& Jenkins, D. (2015). Redesigning America's community colleges: Harvard University Press.

Bandura, A., \& Walters, R. H. (1977). Social learning theory.

Barak, M., Hussein-Farraj, R., \& Dori, Y. J. (2016). On-campus or online: examining self-regulation and cognitive transfer skills in different learning settings. International Journal of Educational Technology in Higher Education, 13(1), 35.

Barnard-Brak, L., Paton, V. O., \& Lan, W. Y. (2010). Profiles in self-regulated learning in the online learning environment. The International Review of Research in Open and Distributed Learning, 11(1), 61-80.

Barnard, L., Lan, W. Y., To, Y. M., Paton, V. O., \& Lai, S.-L. (2009). Measuring selfregulation in online and blended learning environments. The Internet and Higher Education, 12(1), 1-6.

Bekhet, A. K., \& Zauszniewski, J. A. (2012). Methodological triangulation: An approach to understanding data. Nurse Researcher, 20(2), 40-43.

Bidjerano, T. (2005, October 19-21). Gender Differences in Self-Regulated Learning. Paper presented at the Annual Meeting of the Northeastern Educational Research Association, Kerhonkson, NY, USA.

Blum, M., \& Barger, A. (2018). The CASPA model: An emerging approach to integrating multimodal assignments. Journal of Educational Multimedia and Hypermedia, 27(3), 309-321.

Broadbent, J. (2017). Comparing online and blended learner's self-regulated learning strategies and academic performance. The Internet and Higher Education, 33, 24-32.

Calder, N. (2012). The layering of mathematical interpretations through digital media. Educational Studies in Mathematics, 80(1-2), 269-285.

Cho, V., \& Lam, W. (2017). The power of LinkedIn: Will professionals leave their organizations for professional advancement because of their use of LinkedIn? 
Paper presented at the In Pacific Asia Conference on Information Systems PACIS.

Chou, P.-N., \& Chang, C.-C. (2018). Small or Large? The Effect of Group Size on Engineering Students' Learning Satisfaction in Project Design Courses. EURASIA Journal of Mathematics, Science and Technology Education, 14, 10.

Clark, R. C., Nguyen, F., \& Sweller, J. (2011). Efficiency in learning: Evidence-based guidelines to manage cognitive load: John Wiley \& Sons.

Coulson, S., \& Frawley, J. K. (2017). Student-generated multimedia for supporting learning in an undergraduate physiotherapy course. Paper presented at the ASCILITE2017: 34th International Conference on Innovation, Practice and Research in the Use of Educational Technologies in Tertiary Education, Toowoomba, QLD.

Dunnigan, J. E. (2018). The Relationship of Self-Regulated Learning and Academic Risk Factors to Academic Performance in Community College Online Mathematics Courses. Seattle Pacific University,

Edwards, F. (2018). The Relationship between College Student Attitudes towards Online Learning Based on Reading Self-Efficacy, Ethnicity, and Age.

Gorissen, P., Bruggen, J. V., \& Jochems, W. (2013). Methodological triangulation of the students' use of recorded lectures. International Journal of Learning Technology, 8(1), 20-40.

Gurel, D. K., Eryılmaz, A., \& McDermott, L. C. (2015). A Review and Comparison of Diagnostic Instruments to Identify Students' Misconceptions in Science. Eurasia Journal of Mathematics, Science \& Technology Education, 11(5).

Henriksen, B., Henriksen, J., \& Thurston, J. S. (2016). Building Health Literacy and Cultural Competency Through Video Recording Exercises. INNOVATIONS in pharmacy, 7(4), 17.

Hoban, G., Nielsen, W., \& Shepherd, A. (2015). Student-Generated Digital Media in Science Education: Learning, Explaining and Communicating Content. New York, NY: Taylor \& Francis Group.

Hobbs, R. (2017). Create to Learn: Introduction to Digital Literacy. New York, NY: John Wiley \& Sons.

Hobbs, R. (2018). Measuring the digital and media literacy competencies of children and teens. In Cognitive Development in Digital Contexts (pp. 253-274): Elsevier.

Hodges, C. B. (2008). Self-efficacy in the context of online learning environments: A review of the literature and directions for research. Performance Improvement Quarterly, 20(3-4), 7-25.

Jablonski, D., Hoban, G., Ransom, H., \& Ward, K. (2015). Exploring the use of "slowmation" as a pedagogical alternative in science teaching and learning. Pacific-Asian Education Journal, 27(1), 5-20.

Jamani, K. J. (2011). A semiotics discourse analysis framework: Understanding meaning-making in science education contexts. Semiotics theory and applications, 192-208.

Jenson, J. D. (2011). Promoting self-regulation and critical reflection through writing students' use of an electronic portfolio. International Journal of ePortfolio, 1(1), 49-60. 
Johnson, R. L., \& Morgan, G. B. (2016). Survey scales: a guide to development, analysis, and reporting: Guilford Publications.

Kaufmann, R., \& Buckner, M. M. (2018). Revisiting "power in the classroom": exploring online learning and motivation to study course content. Interactive Learning Environments, 1-8.

Kearney, M. (2009). Towards a learning design for student-generated digital storytelling. Kearney, M. (2013). Learner-generated digital video: Using Ideas Videos in Teacher Education. Journal of Technology and Teacher Education, 21(3), 321-336.

Kearney, M., \& Schuck, S. (2005). Students in the director's seat: Teaching and learning with student-generated video. Paper presented at the Proceedings of Ed-Media 2005 World Conference on Educational Multimedia, Hypermedia and Telecommunications.

Kenney, J., \& Newcombe, E. (2018). Supporting Student Self-Regulation: In a Blended, Flipped Learning Format. In Online Course Management: Concepts, Methodologies, Tools, and Applications (pp. 1302-1318): IGI Global.

Kocdar, S., Karadeniz, A., Bozkurt, A., \& Buyuk, K. (2018). Measuring Self-Regulation in Self-Paced Open and Distance Learning Environments. The International Review of Research in Open and Distributed Learning, 19(1).

Kooloos, J. G. M., Klaassen, T., Vereijken, M., Van Kuppeveld, S., Bolhuis, S., \& Vorstenbosch, M. (2011). Collaborative group work: Effects of group size and assignment structure on learning gain, student satisfaction and perceived participation. Medical Teacher, 33(12), 983-988. doi:10.3109/0142159X.2011.588733

Licht, B. G., \& Dweck, C. S. (1984). Determinants of academic achievement: The interaction of children's achievement orientations with skill area. Developmental Psychology, 20(4).

Manzi, C., Coen, S., Regalia, C., Yevenes, A. M., Giuliani, C., \& Vignoles, V. L. (2018). Being in the Social: A cross-cultural and cross-generational study on identity processes related to Facebook use. Computers in Human Behavior, 80, 81-87.

Martin, J. M., \& Zahrndt, J. (2017). Media and Digital Literacies. London, United Kingdom: Lexington Books.

McLoughlin, C., \& Loch, B. (2012). Engaging students in cognitive and metacognitive processes using screencasts. Paper presented at the EdMedia: World Conference on Educational Media and Technology 2012, Denver, Colorado, USA. http://www.editlib.org/p/40891

McMahon, M., \& Oliver, R. (2001). Promoting Self-Regulated Learning in an On-Line Environment.

Miller, D. A. (2015). Learning How Students Learn: An Exploration of Self-Regulation Strategies in a Two-Year College General Chemistry Class. Journal of College Science Teaching, 44(3), 11-16.

Musburger, R. B., \& Kindem, G. (2012). Introduction to media production: the path to digital media production. Burlington, MA: Focal Press.

Nielsen, W., Georgiou, H., Jones, P., \& Turney, A. (2018). Digital Explanation as Assessment in University Science. Research in Science Education. doi:10.1007/s11165-018-9785-9 
Nielsen, W., Hoban, G., \& Hyland, C. (2017). Pharmacology Students' Perceptions of Creating Multimodal Digital Explanations. Chemistry Education Research and Practice.

Niemivirta, M. (1997). Gender Differences in Motivational-Cognitive Patterns of SelfRegulated Learning.

Nota, L., Soresi, S., \& Zimmerman, B. J. (2004). Self-regulation and academic achievement and resilience: A longitudinal study. International Journal of Educational Research, 41(3), 198-215.

Ottenhoff, J. (2011). Learning How to Learn: Metacognition in Liberal Education. Liberal Education, 97, 28-33.

Pardo, A., Han, F., \& Ellis, R. A. (2016). Exploring the relation between self-regulation, online activities, and academic performance: $A$ case study. Paper presented at the Proceedings of the Sixth International Conference on Learning Analytics \& Knowledge.

Pauli, R., Mohiyeddini, C., Bray, D., Michie, F., \& Street, B. (2008). Individual differences in negative group work experiences in collaborative student learning. Educational Psychology, 28(1), 47-58.

Pearce, K. L., \& Vanderlelie, J. J. (2016a). Teaching and evaluating graduate attributes in the multimedia science-based assessment task. Paper presented at the Proceedings of The Australian Conference on Science and Mathematics Education, The University of Queensland, Australia.

Pearce, K. L., \& Vanderlelie, J. J. (2016b). Teaching and evaluating graduate attributes in the multimedia science-based assessment task. Paper presented at the Proceedings of The Australian Conference on Science and Mathematics Education.

Phillips, R., McNaught, C., \& Kennedy, G. (2012). Evaluating e-learning: Guiding research and practice. New York, NY: Routledge.

Pintrich, P. R. (2004). A conceptual framework for assessing motivation and selfregulated learning in college students. Educational psychology review, 16(4), 385-407.

Pintrich, P. R., \& Zusho, A. (2007). Student Motivation and Self-Regulated Learning in the College Classroom. In R. P. Perry \& J. C. Smart (Eds.), The Scholarship of Teaching and Learning in Higher Education: An Evidence-Based Perspective (pp. 731-810). Dordrecht: Springer Netherlands.

Pirhonen, J., \& Rasi, P. (2016). Student-generated instructional videos facilitate learning through positive emotions. Journal of Biological Education, 1-13.

Potter, J., \& McDougall, J. (2017). Digital Media, Culture and Education: Theorising Third Space Literacies. London, UK: Springer.

Powell, L., \& Robson, F. (2014). Learner-generated podcasts: a useful approach to assessment? Innovations in Education and Teaching International, 51(3), 326337.

Reyna, J. (2019). A model to explore learning processes in learner-generated digital media assignments. Paper presented at the 13th International Technology, Education and Development Conference, Valencia, Spain. 
Reyna, J., Hanham, J., \& Meier, P. (2017). A taxonomy of digital media types for Learner-Generated Digital Media assignments. E-learning and Digital Media, 14(6), 309-322. doi:10.1177/2042753017752973

Reyna, J., Hanham, J., \& Meier, P. C. (2018a). A framework for digital media literacies for teaching and learning in higher education. E-learning and Digital Media, 15(4), 176-190.

Reyna, J., Hanham, J., \& Meier, P. (2018b). The Internet explosion, digital media principles and implications to communicate effectively in the digital space. $E$ learning and Digital Media, 15(1), 36-52. doi:10.1177/2042753018754361

Reyna, J., Hanham, J. \& Meier, P. (2018c). A Methodological Approach to Evaluate the Effectiveness of Learner-Generated Digital Media (LGDM) Assignments in Science Education. In T. Bastiaens, J. Van Braak, M. Brown (Eds.), Proceedings of EdMedia: World Conference on Educational Media and Technology (pp. 303314). Amsterdam, Netherlands: Association for the Advancement of Computing in Education (AACE). https://www.learntechlib.org/primary/p/184211/.

Reyna, J., Hanham, J., Vlachopoulos, P., \& Meier, P. (2019). Using factor analysis to validate a questionnaire to explore self-regulation in learner-generated digital media (LGDM) assignments in science education. Australasian Journal of Educational Technology, 35(5), 128-152.

Reyna, J., Horgan, F., Ramp, D., \& Meier, P. (2017). Using Learner-Generated Digital Media (LGDM) as an Assessment Tool in Geological Sciences. Paper presented at the 11th annual International Technology, Education and Development Conference, INTED2017, INTED, Valencia (Spain), 6th-8th of March 2017.

Reyna, J., \& Meier, P. (2018a). Learner-Generated Digital Media (LGDM) as an Assessment Tool in Tertiary Science Education: A Review of Literature. IAFOR Journal of Education.

Reyna, J., \& Meier, P. (2018b). Using the Learner-Generated Digital Media (LGDM) Framework in Tertiary Science Education: A Pilot Study. Education Sciences, 8(3), 106.

Reyna, J., Meier, P., Geronimo, F., \& Rodgers, K. (2016). Implementing Digital Media Presentations as Assessment Tools for Pharmacology Students. American Journal of Educational Research, 4(14), 983-991. doi:10.12691/education-4-14-1

Rich, P. J., \& Hannafin, M. (2009). Video annotation tools technologies to scaffold, structure, and transform teacher reflection. Journal of Teacher Education, 60(1), 52-67.

Salomon, D. (2013). Moving on from Facebook Using Instagram to connect with undergraduates and engage in teaching and learning. College \& Research Libraries News, 74(8), 408-412.

Schunk, D. H., \& Zimmerman, B. J. (1997). Social origins of self-regulatory competence. Educational Psychologist, 32(4), 195-208.

Shen, C., Kasra, M., Pan, W., Bassett, G. A., Malloch, Y., \& O’Brien, J. F. (2018). Fake images: The effects of source, intermediary, and digital media literacy on the contextual assessment of image credibility online. New media \& society, 1461444818799526. 
Sluijsmans, D. M., Brand-Gruwel, S., van Merriënboer, J. J., \& Bastiaens, T. J. (2002). The training of peer assessment skills to promote the development of reflection skills in teacher education. Studies in Educational Evaluation, 29(1), 23-42.

Sørensen, B. H., \& Levinsen, K. T. (2014). Digital Production and Students as Learning Designers. Designs for Learning, 7(1), 54-74.

Suzuki, N., Imashiro, M., Shoda, H., Ito, N., Sakata, M., \& Yamamoto, M. (2018). Effects of Group Size on Performance and Member Satisfaction, Cham.

Tang, K. s., Delgado, C., \& Moje, E. B. (2014). An integrative framework for the analysis of multiple and multimodal representations for meaning-making in science education. Science Education, 98(2), 305-326.

Tashakkori, A., \& Teddlie, C. (2010). Sage handbook of mixed methods in social \& behavioural research. Thousand Oaks, CA: Sage.

Tümay, H. (2016). Emergence, learning difficulties, and misconceptions in chemistry undergraduate students' conceptualizations of acid strength. Science \& Education, 25(1-2), 21-46.

Vanslambrouck, S., Zhu, C., Lombaerts, K., Philipsen, B., \& Tondeur, J. (2018). Students' motivation and subjective task value of participating in online and blended learning environments. The Internet and Higher Education, 36, 33-40.

Vasilchenko, A., Green, D. P., Qarabash, H., Preston, A., Bartindale, T., \& Balaam, M. (2017). Media Literacy as a By-Product of Collaborative Video Production by CS Students. Paper presented at the Proceedings of the 2017 ACM Conference on Innovation and Technology in Computer Science Education.

Virtanen, P., \& Nevgi, A. (2010). Disciplinary and gender differences among higher education students in self-regulated learning strategies. Educational Psychology, 30(3), 323-347.

Webb, N. M., \& Mastergeorge, A. (2003). Promoting effective helping behaviour in peerdirected groups. International Journal of Educational Research, 39(1-2), 73-97.

Weller, K., Bruns, A., Burgess, J., Mahrt, M., \& Puschmann, C. (2014). Twitter and society (Vol. 89): P. Lang.

Wells, J., \& Blincoe, M. (2015). An examination of the use of online resources in a University E-Learning environment. Paper presented at the E-Learn: World Conference on E-Learning in Corporate, Government, Healthcare, and Higher Education.

Wolters, C. A. (1999). The relation between high school students' motivational regulation and their use of learning strategies, effort, and classroom performance. Learning and Individual Differences, 11(3), 281-299.

Zimmerman, B. J. (1989). A social cognitive view of self-regulated academic learning. Journal of educational psychology, 81(3), 329.

Zimmerman, B. J. (1998). Developing self-fulfilling cycles of academic regulation: An analysis of exemplary instructional models.

Zimmerman, B. J. (2002). Achieving academic excellence: A self-regulatory perspective. The pursuit of excellence through education, 85-110.

Zimmerman, B. J., \& Schunk, D. (2011). Motivational sources and outcomes of selfregulated learning and performance. Handbook of self-regulation of learning and performance, 49-64. 
Zimmerman, B. J., \& Tsikalas, K. E. (2005). Can computer-based learning environments (CBLEs) be used as self-regulatory tools to enhance learning? Educational Psychologist, 40(4), 267-271. 